\title{
State of Microbiology in India
}

\author{
Rup Lal
}

(C) Association of Microbiologists of India 2012

Ever since the birth of microbiology in 1674, when Antonie van Leeuwenhoek became the first person to glimpse microbial life in a drop of water through a glass lens, this science dealing with the study of the invisible life has grown boundlessly. In the initial years, microbiology involved chiefly the studies of fermentation and medicine, but as the diversity and the role of these 'wonder bugs' came into light, the scientific basis of this science expanded throughout the world. In India, the field of microbiology focuses on two major aspects-studying the ways through which microbes cause diseases, and attempting to harness the potential of these microbes for applications like fermentation, antibiotic production, cloning vehicles, biotechnological manipulations, bio-control agents, in bioremediation etc. Synonymous to the house keeping genes in an organism that are essential for its survival, microorganisms are the house-keepers of our planet, and play key roles in the recycling of elements and degradation of dead and decaying matter in nature. In the twentieth century, microbiology has further branched out. These branches mainly include industrial microbiology, agricultural or soil microbiology, environmental microbiology, marine microbiology, food microbiology and clinical or medical microbiology. India is still a developing nation and its large population is constantly combating an ever increasing number of many dreadful diseases like tuberculosis, malaria, cholera and HIV infection. This, in turn, is mostly attributed to the increasing development of multiple drug resistance (MDR) in the causative organisms, especially in the case of tuberculosis. Researchers in India are

R. Lal ( $\square)$

Delhi, India

e-mail: ruplal@gmail.com currently involved in understanding the mechanism by which organisms acquire this drug resistance, and hence attempting to identify novel drug targets for such pathogenic MDR bacterial strains. Extensive study in this area, in a number of premier research and teaching institutes as well as sophisticated hospitals with ever advancing scientific expertise and lower cost of conducting medical and pharmaceutical practices, is expected to bring Indian microbiology to the forefront. Secondly, as India is an agrarian economy, major research has been diverted to the microbiological research in this area. This further involves studies pertaining to nitrogen fixation, bioinoculants, rhizosphere, anaerobic decomposition in biogas production, soil enzymes etc. Additionally, several government agencies like the Indian Council of Agricultural Research and Indian Agricultural Research Institute are engaged in constantly supporting research in this aspect for the development of improved crops with resistance against many stress-causing agents. Thirdly, industrialization has resulted in the release of enormous toxic pollutants into the environment that are posing as health hazards. Adding to this is the accumulation of pesticides and insecticides in the environment as an aftermath of comprehensive crop improvement programs run throughout the nation for more than half a century. In this context, microbes have been extensively studied for their degradation potential. Many laboratories across the country are working on the strategies for the waste management of such pollutants. More recently, microbial genetics has been a field which has undergone immense development, and has emerged as a distinct discipline of molecular biology. Several eukaryotic as well as bacterial genomes are also being sequenced and there is now considerable effort towards metagenomic studies in the country. The impact of these studies will be realized in the coming years. 